\title{
Mastectomy skin flap necrosis: challenges and solutions
}

\author{
Stuart A Robertson' \\ Johann A Jeevaratnam² \\ Avi Agrawal ${ }^{2}$ \\ Ramsey I Cutress 3,4
}

'Department of Surgery, University Hospital Coventry and Warwickshire NHS Trust, Coventry, ${ }^{2}$ Department of Breast Surgery, Portsmouth Hospitals NHS Trust, Cosham, Portsmouth, ${ }^{3}$ Department of Breast Surgery, University Hospital Southampton NHS Foundation Trust, Princess Anne Hospital, ${ }^{4}$ Somers Cancer Research UK Centre, Southampton General Hospital Southampton, UK
Correspondence: Stuart A Robertson Department of Surgery, University Hospital Coventry and Warwickshire NHS Trust, Clifford Bridge Road, Coventry CV2 2DX, UK

Email stuart.robertson@uhcw.nhs.uk
This article was published in the following Dove Press journal:

Breast Cancer - Targets and Therapy

13 March 2017

Number of times this article has been viewed

Introduction: Mastectomy skin flap necrosis (MSFN) has a reported incidence of $5 \%-30 \%$ in the literature. It is often a significant and underappreciated problem. The aim of this article was to review the associated challenges and possible solutions.

Methods: A MEDLINE search was performed using the search term "mastectomy skin flap necrosis". Titles and abstracts from peer-reviewed publications were screened for relevance.

Results: MSFN is a common complication and may present as partial- or full-thickness necrosis. Predictive patient risk factors include smoking, diabetes, obesity, radiotherapy, previous scars and severe medical comorbidity. MSFN leads to a number of challenges, including wound management problems, delays to adjuvant therapy, esthetic compromise, implant extrusion, patient distress and financial loss. Careful preoperative planning and meticulous surgical technique may reduce the incidence of MSFN. A number of intraoperative techniques are available to try and predict skin flaps at risk of MSFN. MSFN may be managed operatively or nonoperatively. Early intervention may reduce the morbidity of MSFN in selected cases. Topical nitroglycerin ointment may be beneficial in reducing MSFN following immediate reconstruction, but the evidence base is still limited.

Conclusion: MSFN can result in considerable challenges for the patient and the health care service. This review discusses the management options for this problem.

Keywords: mastectomy, flap, necrosis, complication, breast surgery

\section{Introduction}

Mastectomy remains a common procedure and is performed on approximately half of women with symptomatic breast cancer and a quarter of those with screen-detected breast cancer in the UK. ${ }^{1}$ However, mastectomy skin flap necrosis (MSFN; Figure 1) occurs more commonly than appreciated, with reports in the literature ranging from $5 \%$ to $30 \% .^{2-10}$

The recent UK National Mastectomy and Breast Reconstruction Audit (NMBRA) reported an overall incidence of $\sim 5 \% .^{2}$ This national audit described outcomes in $>18,000$ women undergoing mastectomy with or without reconstruction between January 1, 2008, and March 31, 2009 in the UK. In response to questionnaires collected 3 months after surgery, $4 \%$ of women in the mastectomy-alone group reported that the "breast skin turned dark and died", whereas $6.1 \%$ reported this complication in the immediate reconstruction group and $5.5 \%$ in the delayed reconstruction group. Other series report even higher rates of MSFN for mastectomy with immediate reconstruction, ranging from $7 \%$ to $30 \% .{ }^{3-10}$ Numerous factors may contribute to this high rate, 


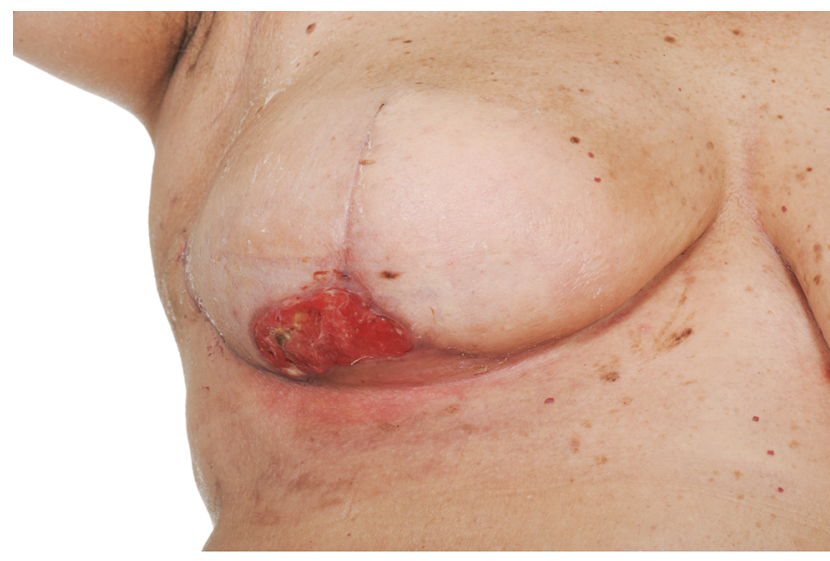

Figure I A photograph showing T-junction MSFN after skin-reducing mastectomy and dermal sling-assisted implant reconstruction.

Note: The dermal sling provided a vascularized bed, protecting the implant beneath and facilitating formation of healthy granulation tissue, permitting healing by secondary intention.

Abbreviation: MSFN, mastectomy skin flap necrosis

including an increasing rate of immediate reconstruction using skin-sparing mastectomy (SSM) and nipple-sparing mastectomy (NSM) techniques (with the preservation of more skin/longer skin flaps) and a move toward more directto-implant reconstructions. ${ }^{11}$ While SSM preserves the native breast skin envelope to optimize esthetic outcomes, immediate reconstruction has been shown to be associated with a higher complication rate than delayed procedures, of which a common early complication is MSFN. ${ }^{12-15}$

MSFN ensues when the blood supply to the skin flaps is insufficient to meet their metabolic needs. It is therefore important to understand how blood is supplied to the breast and the overlying skin. Blood is supplied to the breast via perforating branches from the axillary artery, the internal thoracic artery and the second to fourth anterior intercostal arteries. ${ }^{16,17}$ Perforating cutaneous arterial and arteriolar branches deliver blood to the overlying breast skin, linking to form a continuous plexus. This plexus is best developed subdermally and on the undersurface of the subcutaneous fat. ${ }^{17}$ Interestingly, these subcutaneous vessels are found at a deeper level in breasts with a thicker layer of subcutaneous fat. ${ }^{18}$

There are inconsistencies in the literature as to precisely what is meant by MSFN. Fortunately, a validated scoring system to assess the severity of MSFN has recently been described by the Mayo Clinic called the SKin Ischemia and Necrosis (SKIN) score. ${ }^{19}$ A SKIN score is given based on the depth and area of skin necrosis visible, and this correlates strongly with the need for reoperation. Depth is assessed with a 4-point letter score, with " $\mathrm{A}$ " being no evidence of MSFN through to "D" being full-thickness skin flap necrosis. A

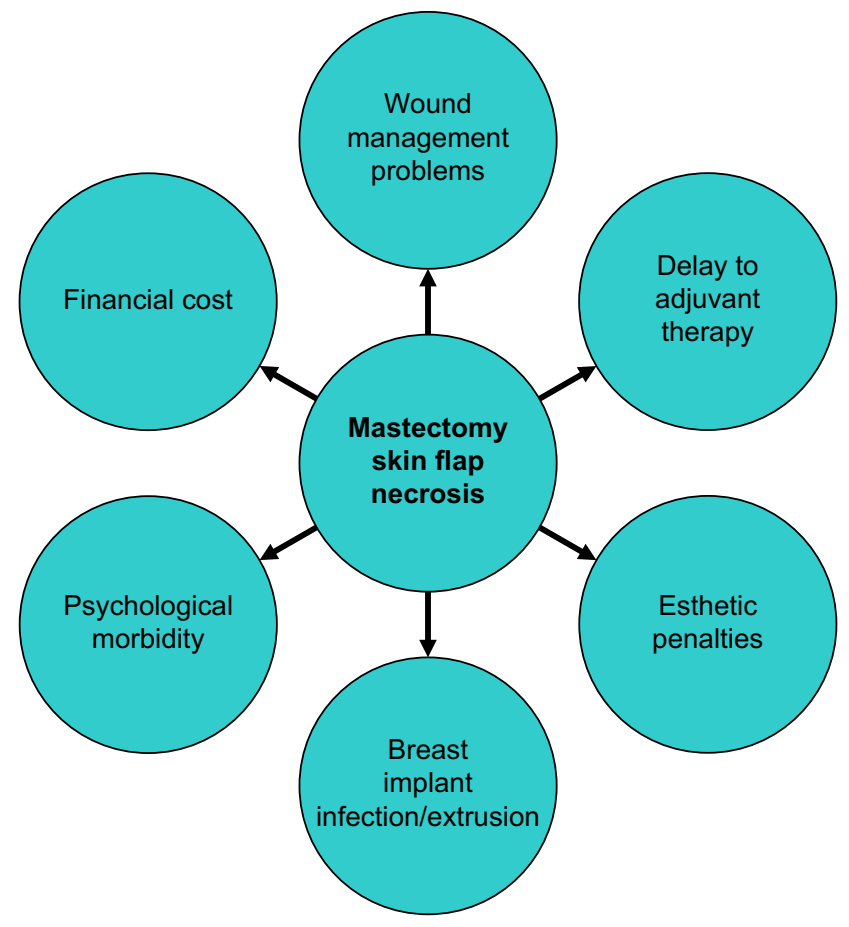

Figure 2 Potential consequences of MSFN.

Abbreviation: MSFN, mastectomy skin flap necrosis.

4-point numerical score is given for the surface area of the deepest necrosis, with " 1 " being assigned for $0 \%$ surface area through to " 4 " being assigned for $>30 \%$ of breast skin (or nipple-areolar complex [NAC] in cases of NSM). This simplified scoring system should allow a more accurate and reproducible description and quantification of MSFN and facilitate comparisons between future studies.

MSFN and wound breakdown lead to a number of challenges. These are summarized in Figure 2 and include immediate and long-term wound management problems, delays to adjuvant therapy and esthetic compromise (particularly to a breast reconstruction) through scarring and distortion. If implants or expanders are used, there is a risk of infection and extrusion. In addition, the psychological morbidity to the patient from the resultant anxiety and distress from these complications should not be underestimated. Strikingly, women who lose their implant have high rates of undergoing no further reconstruction. ${ }^{20}$

The aim of this article was to review the challenges of MSFN, along with possible solutions to this problem.

\section{Methods}

A MEDLINE search was performed in March 2016 using the search term "mastectomy skin flap necrosis" (Figure 3). Abstracts were screened for relevance to the aims of the review. All directly relevant primary studies were included 


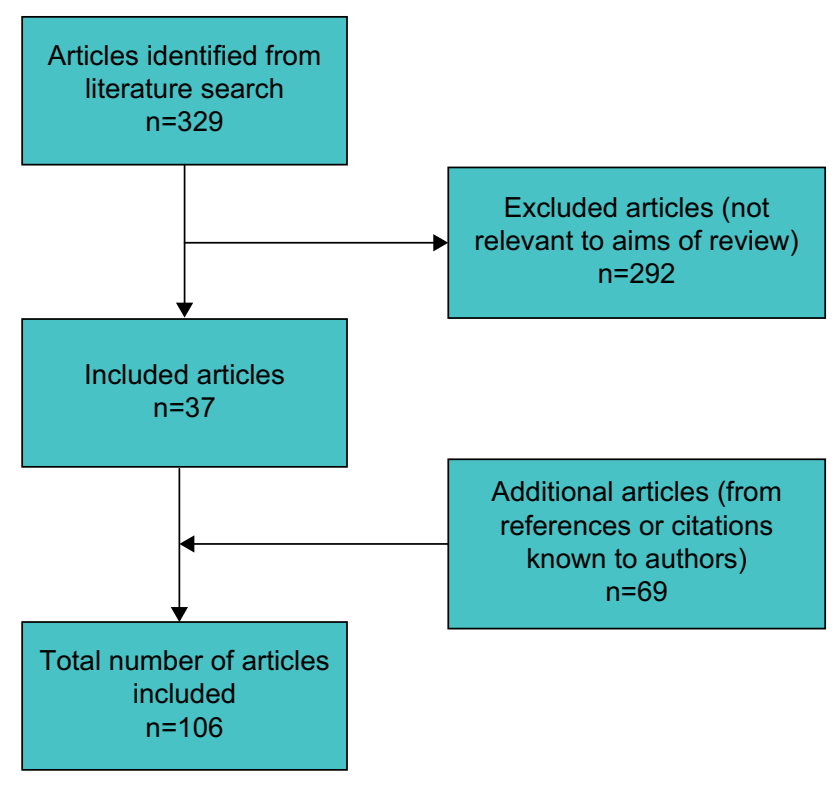

Figure 3 A flow diagram showing selection of articles for review.

and referenced. Articles not relevant to the aims of the review were excluded, as were abstracts and reports from meetings not included in peer-reviewed publications. Additional potentially important references known to the authors, or cited within relevant papers, were also investigated. Only articles published in English were included.

\section{Results}

The search identified 329 papers (Figure 3). Only articles published in English were included. A total of 292 articles were excluded, as they were not relevant to the aims of the review. Abstracts or reports from meetings not included in peer-reviewed publications were also not included. In all, 69 additional potentially important articles known to the authors, or cited within relevant papers, were included, giving a total of 106 articles used for the review. The results of this MSFN review are presented in the following sections.

\section{Challenges}

MSFN and wound breakdown produce a range of challenges, including but not limited to immediate and long-term wound management problems, delays to adjuvant therapy, esthetic penalties through scarring and distortion, risk of infection and implant extrusion, psychological morbidity to the patient (through anxiety and distress) and increased financial expenditure. These are illustrated in Figure 2 and outlined in more detail in the following.

MSFN may present as partial- or full-thickness necrosis. One of the difficulties in reviewing the literature is the inconsistency in the definition of MSFN, as superficial wound breakdown may be managed very differently (eg, with local wound care) than full-thickness necrosis (which may require surgical debridement). Management options for MSFN are discussed further later, but whichever option is chosen, there is oncological importance to start adjuvant chemotherapy or radiotherapy as soon as clinically possible. This is commensurate with National Institute for Health and Care Excellence (NICE) guidance to start adjuvant therapy within 31 days of completion of surgery (NICE guideline CG80 section 1.6.8) and the European Society of Medical Oncology guidelines indicating that treatment should ideally start within 2-6 weeks of surgery. Several papers have shown that SSM and NSM do not lead to significant delays to the start of adjuvant therapy, even when reoperation for skin flap complications is required..$^{21,22}$ However, oncologists may be understandably reluctant to administer chemotherapy or radiotherapy during compromised or delayed wound healing. More light may be shed upon the possibility of delay to adjuvant therapy following immediate breast reconstruction, when the results from the National UK Immediate Breast Reconstruction and Adjuvant Therapy Audit (iBRA-2) are published (http://ibrastudy.com/iBRA2.php).

Scarring and distortion from MSFN can and will lead to esthetic penalty, whether that is a thicker, wider or distorted scar following a simple mastectomy without reconstruction, through to distortion of the skin envelope in SSM or NSM, or even implant extrusion in implant-based reconstruction. Implant-based reconstruction accounts for approximately a third of all breast reconstructions in the $\mathrm{UK}^{2}$ and around three-quarters of all reconstructions in the US. ${ }^{23}$ Complications can occur in up to $40 \%$ of cases, ${ }^{24}$ and $40 \%$ of patients may require revisional surgery. ${ }^{25}$ Over the last decade, implant-based reconstruction techniques have evolved from traditional two-stage procedures through to a single-stage procedure. Two-stage procedures involve initial placement of an expander (often with total submuscular coverage in a subpectoral pocket) followed by a second procedure to replace this with a definitive implant. Single-stage procedures involve the placement of a definitive implant usually in a subpectoral pocket, with either a dermal sling or a biological or synthetic mesh to provide inferolateral implant coverage. ${ }^{26,27}$ Immediate implant-based breast reconstruction is now usually combined with an SSM or NSM technique. However, there is still relatively little high-quality evidence comparing the benefits and complication rates of these new procedures, and so the UK Implant Breast Reconstruction evAluation (iBRA) study is currently prospectively investigating and evaluating these outcomes (http://ibrastudy.com/Home.php). 
Patients experiencing visible necrosis of the skin, wound breakdown or discharge, may encounter psychological morbidity such as anxiety and depression, with a decline in their quality of life. MSFN has been shown to negatively impact on patient satisfaction and quality of life. ${ }^{28}$ Combined with the challenges of receiving a breast cancer diagnosis, recovering from surgery and adapting to changes in the appearance and feel of one's own body following mastectomy, the subsequent additional burden of MSFN can be particularly difficult during the very challenging and vulnerable postoperative period. ${ }^{29-31}$ Support from the patient's breast care nurse specialist can be particularly valuable, alongside that from her surgeon and general practitioner.

The prolonged wound management with skin flap necrosis, including outpatient appointments, dressings and equipment and possibly repeat admission and surgery if indicated all produce an additional financial burden on health care resources. ${ }^{32} \mathrm{~A}$ retrospective study from Baltimore in the US suggests that MSFN results in a 50\% increase in the cost of inpatient charges within 30 days of mastectomy and tissue expander reconstruction. ${ }^{33}$ At a time when health care systems around the world are under pressure for increased efficiency savings, with the UK's National Health Service no exception to this,${ }^{34}$ it is important to consider techniques for anticipating and avoiding MSFN.

\section{Prediction}

Skin flap viability may be influenced by both patient and surgical factors. If mastectomy skin flap perfusion with sufficient oxygenated hemoglobin is compromised, necrosis may ensue.

\section{Patient risk factors for skin flap necrosis}

Patient risk factors include smoking, ${ }^{14,35-43}$ age, ${ }^{14,37,38,44,45}$ hypertension, ${ }^{14,45}$ previous scars, ${ }^{40}$ radiotherapy, ${ }^{13,15,21,35,40,42,44,46}$ diabetes, ${ }^{21}$ obesity, ${ }^{13,14,21,35,38,40,42-45,47-52}$ increased breast volume $^{38,48,53}$ and severe comorbidities. ${ }^{13,54-56}$

Smoking impairs wound healing and significantly increases the risk of MSFN following reconstruction..$^{55}$ The purported mechanism of action of smoking on MSFN may be via nicotine (a known vasoconstrictor), reduced oxygenation of hemoglobin (via carbon monoxide binding) and increased platelet aggregation. ${ }^{36,57-59}$

There is certainly evidence that smoking cessation prior to surgery reduces postoperative complications, as shown in a systematic review and meta-analysis. ${ }^{60}$ This review examined a range of postoperative complications with different types of surgery and found that the longer the cessation the better, with each week of cessation increasing the magnitude of effect by $19 \%$. However, it is unclear specifically how much smoking cessation is required to reduce MSFN, and this may not always be achievable in the often short time between diagnosis and surgery. Results from an experimental rat model investigating the duration of smoking cessation and its impact on skin survival with random pattern flaps suggest that 4 weeks of preoperative smoking cessation is required for significant decreases in the rates of skin flap necrosis. ${ }^{61}$

While electronic cigarettes, or "vaping", do not contain tobacco constituents, they still contain variable amounts of their primary constituent nicotine. Nicotine is known to cause vasoconstriction and inhibition of endothelial-dependent vasodilatation, and so skin flaps with a fragile blood supply may still be placed at risk in patients substituting electronic cigarettes for traditional cigarettes. ${ }^{62}$

Previous breast conserving surgery (wide local excision and radiotherapy) may increase the incidence of MSFN, presumably mediated in part by the effects of previous chest wall radiotherapy. ${ }^{63}$

Advancing age alone does not appear to be a risk factor for surgical complications following microvascular breast reconstruction (including MSFN) according to a retrospective series from Los Angeles. ${ }^{64}$ Moreover, it is specifically an increased number of medical comorbidities and a poorer American Society of Anesthesiologists (ASA) grade that are predictive of surgical complications. Therefore, the overall health status of the patient seems to be more predictive of surgical complications than age alone.

Diabetes mellitus is generally considered a risk factor for vascular complications, owing to a range of vascular abnormalities that can develop, including altered blood viscosity, abnormalities in intimal repair and abnormalities in endothelial cell, red cell and platelet function. A retrospective review from the MD Anderson Cancer Center reported 893 free transverse rectus abdominis myocutaneous (TRAM) flap reconstructions and found no difference in flap complications in diabetic patients, provided euglycemia was maintained. ${ }^{65}$ Specifically, there was no significant difference in terms of the MSFN rate in subgroups with insulin-dependent diabetes mellitus (IDDM; 9.8\%) and non-insulin-dependent diabetes mellitus (NIDDM; 5.3\%) and the nondiabetic group (7.7\%). However, only patients with euglycemia were included in this series, which may limit the broader application of these interesting findings to every diabetic patient being considered for mastectomy.

A large retrospective review of 718 patients undergoing mastectomy and immediate breast reconstruction in British Columbia looked for factors associated with MSFN. ${ }^{42}$ The 
overall rate of MSFN was $12.9 \%$ in this series with a number of patient and surgical risk factors identified as predictors of MSFN. Body mass index (BMI) $>30$, smoking and preoperative radiation were independent predictors of MSFN. Surgical factors included a longer duration of surgery and a Wise pattern mastectomy incision. There was no difference in the MSFN rate between immediate autologous versus implantbased reconstruction methods in this series.

Mlodinow et $\mathrm{al}^{37}$ looked for factors predicting MSFN following immediate tissue expander breast reconstruction in their institution. In all, 1566 mastectomies were reviewed, with an MSFN rate of $8.6 \%$. Regression analysis revealed smoking status, increased age, tumescent mastectomy technique and high intraoperative expander fill volumes ( $>66.67 \%$ ) to be associated with an increased risk of MSFN.

A retrospective review from Harvard of all immediate microsurgical breast reconstructions at a single center investigated risk factors predictive of MSFN. ${ }^{66}$ The MSFN rate in this large series of 746 reconstructions was $13.4 \%$. Univariate analysis revealed a significantly higher incidence of MSFN in patients with a higher mastectomy weight $(p<0.001)$, higher autologous flap weight $(p<0.001)$, higher $\operatorname{BMI}(p=0.002)$ and diabetes mellitus $(p=0.021)$. Multivariate analysis showed significant associations between MSFN and both increasing mastectomy weight (odds ratio [OR] $=1.348$ per quartile increase, $p=0.009)$ and diabetes $(\mathrm{OR}=2.356$, $p=0.011$ ). Possible explanations for the increased MSFN rate with larger mastectomy weights could be the larger skin flap surface area with the larger breast volume or perhaps increased skin tension on the flaps following reconstruction. These predictors may be particularly helpful in preoperative counseling and procedure selection.

The majority of the literature investigating risk factors for MSFN is limited to retrospective series, with inconsistencies in the definition of MSFN and patient selection. However, Matsen et al ${ }^{10}$ have recently published a prospective study to address these limitations. This prospective study measured MSFN rates (scoring it mild, moderate or severe) and measured pre-, peri- and postoperative variables to look for associated factors, with 8 weeks of follow-up. A total of 606 consecutive mastectomies ( $\mathrm{SSM}=84 \%$ and $\mathrm{NSM}=16 \%$ ) with immediate reconstruction (implant or expander based $=94 \%$ and autologous $=6 \%$ ) were performed. A total of 85 (14\%) cases experienced some form of MSFN. In all, $46(8 \%)$ MSFN were mild, $6(1 \%)$ were moderate and 31 (5\%) were severe. The median size of the necrotic tissue, reported as the largest single dimension, was $3 \mathrm{~cm}$ (range: 0-24 cm), $9 \mathrm{~cm}$ (range: $1.5-15 \mathrm{~cm}$ ) and $8 \mathrm{~cm}$ (range: $0.5-26 \mathrm{~cm}$ ), respectively.
A total of 25 of the severe necrosis cases were not healed by 8 weeks following surgery. Nine breasts underwent debridement in theater, and four implants were lost. Univariate analysis for any MSFN showed smoking, history of breast augmentation, NSM and time from incision to specimen removal to be significant. In multivariate analysis, nipple sparing, time from incision to specimen removal, sharp dissection and previous breast reduction were significant for any necrosis. NSM was associated with higher rates of MSFN for every severity. In those with moderate or severe MSFN, univariate analysis showed BMI, diabetes, NSM, specimen size and expander size to be significant. Multivariate analysis showed NSM and specimen size to be significant. Interestingly, the majority of MSFN was mild in this prospective study (the degree of necrosis being difficult to measure and quantify in retrospective studies) and so did not delay adjuvant therapy. Moderate necrosis and severe necrosis were less common, and return to theater and implant loss rates were $<2 \%$ in these groups. This may be due to their policy of full muscle coverage for expander-based reconstructions.

\section{Surgical technique and skin flap viability}

Surgical factors increasing the risk of MSFN include higher mastectomy weight; ${ }^{43,48}$ incision type, ${ }^{6,47,67-69}$ including the Wise pattern mastectomy incision; ${ }^{48}$ decreased mastectomy skin flap thickness, ${ }^{70}$ volume of tissue expander fill ${ }^{45}$ and perhaps the mastectomy technique itself, such as the use of tumescence. ${ }^{37,44,45,47}$

Lee et $\mathrm{al}^{11}$ performed a review of the rate of mastectomy flap complications for NSM and reconstruction at their institution. They found higher rates of mastectomy flap complications, including mastectomy flap necrosis and nipple loss, in implant-based rather than autologous techniques. This initially seems somewhat surprising, as one might have expected the autologous group to have more risk factors for MSFN, such as a longer operative time, and perhaps, this technique is selected more often in women with larger, more ptotic breasts, who may also tend to have a higher BMI. However, the patient- and procedure-related characteristics were reportedly similar between the groups in this review. Whatever may be the true explanation for the differences observed in mastectomy flap complications between the groups, this is an interesting finding in light of the trend toward increased numbers of implant-based reconstructions now being performed.

The determinants of optimum mastectomy flap thickness have previously been reviewed. ${ }^{70} \mathrm{~A}$ balance must be obtained during mastectomy between achieving clear resection margins, 
while not making the flaps so thin that they risk flap necrosis. This is achieved through careful adherence to the oncoplastic plane between the subcutaneous fat and the breast parenchyma. Subcutaneous tissue thickness can be extremely variable and does not correlate with BMI, patient age or the thickness in the other breast. ${ }^{71}$ The oncoplastic plane may be difficult to identify in some patients and a distinct superficial fascial layer may be absent in up to $44 \%$ of patients. ${ }^{72}$ However, once identified, close adherence to it is crucial to achieving both an oncologically sound SSM while preserving the blood supply to the skin. Along with meticulous surgical technique, a good knowledge of the blood supply to the skin and nipple of the breast may help to avoid MSFN in SSM and NSM. ${ }^{73}$

Neoadjuvant therapy may help downsize tumors that are close to the skin, or adjuvant chest wall radiotherapy may be utilized for close resection margins, which might help avoid the need for overly thin skin flaps. MSFN rates close to $17 \%$ have been reported with flaps 4-5 mm thick, ${ }^{74}$ whereas others have achieved rates of $<5 \%$ with thicker $10 \mathrm{~mm}$ flaps, ${ }^{75,76}$ suggesting that thicker flaps may reduce rates of MSFN. However, these reports are only case series and not randomized controlled trial (RCT) evidence, and the measurement methods for thickness are not standardized and are therefore difficult to reproduce.

There are of course various operator technical factors that may reduce the chances of MSFN, such as careful tissue handling (especially while raising the mastectomy flaps), avoiding tension during closure (especially important with Wise pattern incisions) and respecting the oncoplastic plane of dissection for mastectomy flaps, so they are not fashioned overly thin.

While preservation of more breast skin during mastectomy (as in SSM or NSM) may improve the esthetic results of breast reconstruction, MSFN rates remain high with this technique. ${ }^{77} \mathrm{NSM}$ is a significant predictor of MSFN, as well as nipple areolar necrosis, and has been associated with higher complication rates in several studies. ${ }^{6,10,53,78}$

Higher rates of MSFN have also been reported with the use of Wise pattern skin-reducing mastectomy techniques and immediate reconstruction for large breast volumes. ${ }^{79}$ In this retrospective series, mastectomy weight was significantly associated with skin complications requiring surgery (age-adjusted OR per $100 \mathrm{~g}=1.6$, CI $1.1-2.3, p=0.02$ ). This might be expected to some extent, as Wise pattern reduction techniques are inherently at risk of "T junction" necrosis, and larger breasted individuals requiring skin reduction may carry other contributory patient risk factors, such as an elevated BMI. As always, minimizing skin tension is crucial in avoiding MSFN in Wise pattern techniques.

Some surgeons inject saline into the subcutaneous plane (often with local anesthetic and/or adrenaline), to perhaps "hydrodissect" the breast off the skin flap if performed under pressure or at least to make the fascial plane thicker and easier to adhere to, while also purportedly minimizing blood loss and the use of diathermy. It is argued that the liquid finds the plane of least resistance between the subcutaneous fat and the fat of the glandular breast tissue below. Anecdotally, this approach seems quite popular and effective across different units. However, the literature reports contrasting experiences with tumescence. Two retrospective case series urge caution, reporting this as a risk factor for the development of postoperative skin flap necrosis, while two more recent studies (one prospective) did not find tumescence to be a significant factor for MSFN. Chun et $\mathrm{al}^{44}$ reported tumescent mastectomy technique as a significant risk factor for MSFN after mastectomy and immediate reconstruction in a retrospective series of 380 consecutive cases (OR $=3.98, p<0.001)$. Other risk factors in this series included previous irradiation, age and BMI. Mlodinow et $\mathrm{al}^{37}$ also reported tumescent mastectomy technique to be associated with MSFN in their large series of 1566 immediate tissue expander reconstructions. However, these retrospective series do not prove causality. However two very recent publications indicate that tumescence is not a significant risk factor for MSFN. ${ }^{10,80}$ These contrasting findings suggest that other factors may be involved.

It has also been suggested that the use of diathermy rather than scalpel dissection may increase the MSFN rate, presumably via coagulation injury to the adjacent subdermal plexus. However, in a retrospective study of $151 \mathrm{SSMs}$, there was no significant difference between diathermy and scalpel dissection. $^{48}$

Carlson et $\mathrm{al}^{81}$ have looked at predisposing factors for nipple ischemia after NSM in a prospective series of 71 NSMs. In all, 40 mastectomies were for cancer and 31 were risk reducing ( $\mathrm{n}=45$ patients). The majority were expander or implant reconstructions, with only three flap-based reconstructions. Partial nipple necrosis occurred in $28.2 \%$ of cases, and the majority healed uneventfully, with only one case requiring secondary nipple reconstruction. Higher rates of nipple necrosis occurred with periareolar incisions $(\mathrm{OR}=9.69, \mathrm{CI}: 1.57-59.77, p=0.014)$ or excision of the ducts from the undersurface of the nipple $(\mathrm{OR}=10.54, \mathrm{CI}$ : 1.88-59.04, $p=0.007$ ). 


\section{Detection}

A number of methods and devices have been used to assess tissue perfusion intraoperatively in order to try and avoid mastectomy flap necrosis, but none have achieved universal acceptance. Intraoperative devices are often not readily available in all hospitals and can be expensive or time consuming when compared to traditional methods of clinical evaluation of skin flap perfusion. Therefore, in resource-limited environments, their use may be best reserved for operations at a higher risk of MSFN. The various different methods of evaluation have been reviewed and helpfully summarized in a tabulated form, along with supporting references, by Gurtner et al.$^{82}$ The ideal system would allow accurate identification of the supplying vessels (and their corresponding perfusion zones), accurate assessment of tissue perfusion and delineation of vulnerable tissue at risk of necrosing. For breast reconstruction, particularly implant based, the earlier the MSFN is detected, the better it is. Ideally, areas of nonviable skin or areas of dubious viability would be detected intraoperatively, permitting excision during the mastectomy, before necrosis ensues. For implant-based reconstructions, it may also provide an opportunity to consider choosing a smaller implant or perhaps choosing an expander in such cases, according to the surgeon's judgment and preference.

If ischemic areas are not identified intraoperatively, early postoperative detection may still allow excision and resuturing and may save an underlying implant from potential infection and extrusion. ${ }^{83}$

Clinical evaluation of flap perfusion has been the traditional and most widely used method to assess the adequacy of the remaining blood supply, once the underlying breast has been removed. ${ }^{84}$ Traditional methods of skin flap viability assessment include assessment of skin color, capillary refill, skin temperature and dermal bleeding. However, clinical evaluation alone has its limitations ${ }^{85,86}$ leading to the development of several technologies that can be used intraoperatively, including handheld Doppler, ${ }^{87}$ laser Doppler flowmetry, ${ }^{88,89}$ fluorescein angiography ${ }^{56,90,91}$ and indocyanine green angiography. ${ }^{92}$

Doppler ultrasound is somewhat limited by being inherently operator dependent, while laser Doppler flowmetry may underestimate flap survival and the equipment is large. Fluorescein dye testing has been used to evaluate skin flaps in plastic surgery for many years and may play a role in the evaluation of equivocal mastectomy flap viability, allowing excision of areas with poor perfusion unlikely to survive. The fluorescein dye is injected intravenously, and a wood's lamp is used to evaluate flap fluorescence. Losken et $\mathrm{al}^{56}$ studied this in the periareolar skin of 50 SSM flaps. Flaps with areas of nonfluorescence $>4 \mathrm{~cm}^{2}$ tended not to survive, while areas $<4 \mathrm{~cm}^{2}$ typically would survive, except in the irradiated breast. However, fluorescein techniques are limited by the long half-life of the contrast medium, preventing reevaluation during the intraoperative period and risking false positives.

Indocyanine green contrast agent has shown some encouraging results in the intraoperative assessment of mastectomy flap perfusion and prediction of subsequent flap necrosis. A large case series from Emory University has looked specifically at indocyanine green angiography in predicting MSFN in a prospective cohort of 118 patients undergoing SSM and breast reconstruction. ${ }^{77}$ In all, 14 patients experienced postoperative skin flap necrosis. Skin with $\leq 25 \%$ perfusion was not viable $90 \%$ of the time, while areas with $\geq 45 \%$ perfusion survived $98 \%$ of the time. This may be a useful adjunct to the prediction and avoidance of MSFN. Intraoperative indocyanine laser perfusion assessment tools, such as the SPY system (LifeCell Corp., Branchburg, NJ, USA), have been used to identify mastectomy skin flaps at risk of subsequent ischemia and necrosis. ${ }^{93}$ Indocyanine green was used to evaluate mastectomy flap perfusion in 39 patients undergoing mastectomy and immediate breast reconstruction with a prosthesis, and this was compared to 52 patients in the pre-SPY era. The postoperative complication rate in this retrospective study was reported as twofold higher in the pre-SPY group, but this did not reach statistical significance $(p=0.06)$. However, the number of repeat visits to theater was significantly higher in the pre-SPY era. Five of the seven patients with complications in the post-SPY group were identified by SPY as having poor flap perfusion, but none were identified with clinical judgment alone. The main limitations of this study were its small size and retrospective nonrandomized design, but it still suggests that the SPY system may be able to contribute perioperatively to the identification of tissue at risk of ischemia and necrosis. Indocyanine green has also been used to describe specific NAC perfusion patterns and may be a helpful adjunct in evaluating higher risk perfusion patterns in NSM to try and avoid ischemic complications. ${ }^{94}$

Indocyanine green angiography has the advantage of a short half-life and good safety profile. It is also cleared rapidly from tissues, facilitating repeat evaluations of tissue perfusion during the same procedure. It may have advantages over clinical evaluation or fluorescein techniques in predicting MSFN. ${ }^{43}$ However, although this method may aid in predicting necrosis, it only appears cost-effective if used 
selectively for high-risk cases. ${ }^{95} \mathrm{~A}$ prospective trial has compared two intraoperative vascular imaging techniques with clinical assessment to assess mastectomy skin flap perfusion to predict areas of necrosis. ${ }^{43}$ Laser-assisted indocyanine green dye angiography, fluorescein dye angiography and clinical assessment were all compared to evaluate the skin flaps of 51 tissue expander-implant reconstructions $(n=32$ patients). In all, 21 cases (41.2\%) underwent "all-inclusive necrosis", of which 6 cases were full thickness; 5 (9.8\%) of these cases required intervention. Unsurprisingly, statistically significant risk factors for necrosis included smoking, obesity and a breast weight of $>1 \mathrm{~kg}$. However, laser-assisted indocyanine green dye angiography and fluorescein dye angiography overpredicted areas of necrosis by $72 \%$ and $88 \%$, respectively $(p=0.002)$. The laser-assisted indocyanine green dye angiography was a better predictor of MSFN and more specific than fluorescein dye or clinical assessment, but would overpredict MSFN without quantitative analysis.

The intraoperative oxygen tension of mastectomy skin flaps can be measured, as reported in a pilot study by Rao et al. ${ }^{96}$ In this small series of 10 patients undergoing simple mastectomy or SSM, only one patient developed flap necrosis and the authors identified a reduction in skin flap oxygen saturation and flap length as predictors of this. This noninvasive technique requires further evaluation before any recommendations can be made regarding its use in MSFN prediction.

\section{Avoidance}

Unfortunately, many patient risk factors are not modifiable in the time scale between diagnosis and surgery. Where patients are assessed as having a high risk of MSFN, performing a simple mastectomy with a delayed reconstruction may permit not only the timely administration of any adjuvant therapy but also more time for modification of any adjustable risk factors prior to reconstruction.

Very large tumors may benefit from downsizing with neoadjuvant therapies prior to surgery in selected suitable patients, which may avoid the need to fashion ever-thinner mastectomy skin flaps to achieve tumor clearance and thus reduce the chances of MSFN. Consideration ought to be given within the multidisciplinary team (MDT) as to which patients might benefit from neoadjuvant chemotherapy ${ }^{97}$ or neoadjuvant endocrine therapy. ${ }^{98,99}$

Khavanin et $\mathrm{a}^{45}$ performed a retrospective review of 966 consecutive patients undergoing SSM or NSM and expander-based reconstruction at a single institution in Chicago between 2004 and 2012. They were looking for risk factors for MSFN requiring surgical excision and found that necrosis rates were higher in the high fill cohort than in the low fill cohort $(10.4 \%$ vs $7.1 \%, p=0.027$ ). However, multivariate logistic regression did not identify high expander fill volumes as an independent risk factor for MSFN. Interestingly, four risk factors were identified that acted synergistically with high fill volume to increase the risk of MSFN, namely, tumescence (synergy index $[\mathrm{SI}]=25.3$ ), followed by hypertension ( $\mathrm{SI}=2.39$ ), obesity $(\mathrm{SI}=2.28$ ) and age $>50$ $(\mathrm{SI}=1.17)$. Acellular dermal matrix $(\mathrm{ADM})$ use was not associated with MSFN in this study. The authors suggest that the epinephrine in the tumescent solution may reduce dermal blood flow sufficient to put the flap at risk of necrosis, while the small vessel disease associated with the other three risk factors may also decrease mastectomy skin flap perfusion, which then go on to manifest as full-thickness necrosis in the setting of high intraoperative fill volumes. This study has significant limitations of course, not least the retrospective nature, being from a single center and only addressing those variables documented in the records, when other factors may be at play. However, despite these limitations, using smaller intraoperative inflation volumes for expanders in higher risk cases may reduce the incidence of significant MSFN.

Interestingly, Gdalevitch et $\mathrm{a}^{100}$ from the University of British Columbia have recently reported the results of an RCT into the effects of applying nitroglycerin ointment (a potent topical vasodilator of both arteries and veins) to mastectomy skin flaps following immediate reconstruction. A single application of $45 \mathrm{mg}$ of nitroglycerin ointment (2\%) was applied to the mastectomy skin flaps at the end of the operation at the time of dressing application, and the dressings were left in place for 48 hours. They terminated the study after 165 patients had been recruited ( 85 to treatment, 80 to placebo), as the interim analysis showed a significant reduction in MSFN in the group receiving the nitroglycerin ointment (15.3\% flap necrosis rate) versus placebo (33.8\% flap necrosis rate, $p=0.006)$. They concluded that the application of this vasodilator "is a simple, safe and effective way to help prevent mastectomy skin flap necrosis". However, the evidence base in support of its widespread use is still somewhat limited as this was only a single study of 165 patients.

\section{Treatment}

MSFN can be managed operatively or nonoperatively. Operative management first necessitates debridement of necrosed tissue and then several options to deal with the skin loss, including resuturing, replacing skin (with grafting or flaps), conversion to another breast reconstruction (where indicated) and allowing healing by secondary intention. Nonoperative options involve allowing the necrosed tissue to shed and subsequent healing by 
secondary intention, but this requires regular and active wound management entailing numerous dressing changes, often over a prolonged period, while this process occurs. Wound management devices, such as vacuum dressings, may aid wound healing, particularly for larger areas of necrosis.

No clearly defined course of action exists, with management often decided on a case-by-case basis, in line with the surgeon's preference. The risk of further operation in order to expedite wound healing must be weighed up against a protracted course of wound healing, requiring long-term dressing care. Some feel that patients at a higher risk of MSFN, or with full-thickness defects, should be treated more aggressively. ${ }^{9}$ Patients awaiting the timely administration of adjuvant therapy may benefit from operative management to try and expedite wound healing. ${ }^{101}$

\section{Nonoperative management}

Nonoperative management remains the favored course of action for MSFN following simple mastectomy, or with autologous reconstruction, with skin grafts reserved for massive skin necrosis. ${ }^{21}$ Allowing the wound to heal by natural wound contraction and re-epithelialization may lead to less significant contour defect and avoid the patch appearance of a skin graft. ${ }^{4}$ The use of hyperbaric oxygen has had successful results within case reports, but has no robust evidence to support its use. ${ }^{102,103}$

Nonoperative management involves the use of dressings, such as alginates and silver preparations (to reduce bacterial burden) in a dynamic manner, adapting to wound appearance, improvement and patient preference. Antimicrobials may be required in case of infection, while small areas of eschar may be debrided in the outpatient setting. ${ }^{4,101}$ Wound management devices, such as vacuum dressings, may facilitate wound healing, particularly where larger areas of necrosis are encountered.

\section{Operative management}

Consideration of early operative intervention for MSFN is particularly important where there is an underlying implant reconstruction. Partial-thickness MSFN with an underlying vascularized dermal sling may be suitable for nonoperative management (Figure 1). However, where an ADM has been used, consideration should be given to early excision of any skin necrosis and resuturing, to try and save the implant from extrusion. ${ }^{83}$

Where the risk of MSFN is considered to be very high during mastectomy, other operative management strategies may involve the use of skin banking ${ }^{104}$ or skin grafts, which may be split or full thickness, using redundant abdominal dog ear tissue, for example. ${ }^{9}$
Skin banking is a method of delayed inset of the flap the autologous tissue is not de-epithelialized at the time of primary reconstruction and is placed into the subcutaneous pocket, providing options where there is questionable viability of skin flaps, should native mastectomy skin necrose. ${ }^{4,104}$ However, this does commit the patient to a second operation and therefore should perhaps be reserved sparingly for patients with multiple risk factors, where it is considered very likely that they will experience skin necrosis.

There has been a report of excising a questionably viable skin flap, thinning it and then replacing it as a full-thickness skin graft following radical mastectomy. ${ }^{105}$ While this was reported in relation to radical mastectomies in the $1970 \mathrm{~s}$, it could be theoretically applicable to any graftable bed, but is not widely used.

Rates of NSM are on the increase, but this procedure carries with it the attendant risk of nipple necrosis. This has been extensively reviewed by O'Connell and Rusby and may be avoided through a combination of careful surgical technique and a good working knowledge of the skin and nipple vasculature. ${ }^{73}$ However, when it does occur, it may be treated by excision of the nipple.

The technique of "surgical delay" has been reported to improve NAC survival rates. ${ }^{106}$ This is where the NAC is disconnected from the tissue beneath a few weeks prior to NSM, allowing not only the blood supply from the adjacent breast skin to augment but also confirmation of clear retroareolar margins. If the biopsy proves to be involved, the NAC can then be removed at the subsequent mastectomy. Jensen et al reported very good NAC survival rates with this technique.

\section{Conclusion}

This article has reviewed the challenges of MSFN, along with possible solutions. In summary, MSFN occurs more frequently than perceived, reported somewhere in the range of $5 \%-30 \%$ of cases in the literature. MSFN may be partial or full thickness. A SKIN score based on depth and extent correlates with the need for reoperation. Patient risk factors for MSFN include a history of smoking, obesity, diabetes, previous radiotherapy, previous scars and severe medical comorbidities. Careful preoperative planning may reduce the chances of MSFN, such as modification of patient risk factors (where feasible), consideration of neoadjuvant therapies and considering the most appropriate type of and timing of reconstruction for that individual's risk profile, for example, perhaps avoiding immediate SSM in very high-risk cases.

Surgical technique plays an important role in avoiding MSFN, including optimizing mastectomy skin flap thickness 
and using the oncoplastic plane. A number of intraoperative techniques have been developed to detect areas of skin at risk of MSFN, including clinical evaluation, handheld Doppler devices, laser Doppler, fluorescein angiography and indocyanine green techniques. MSFN leads to a number of challenges, including immediate and long-term wound management problems, delays to adjuvant therapy, esthetic penalty, risk of infection and extrusion of breast implants, psychological morbidity and an increased financial burden. A recently published RCT has reported that nitroglycerin ointment applied to mastectomy skin flaps following immediate reconstruction may reduce the incidence of MSFN, but the evidence base is still limited. MSFN may be managed operatively or nonoperatively, depending on the individual case. Early intervention in selected cases may avoid or reduce some of the possible adverse consequences, such as implant loss.

\section{Acknowledgment}

Research by RIC is supported by Cancer Research UK and Breast Cancer Now.

\section{Disclosure}

The authors report no conflicts of interest in this work.

\section{References}

1. Lawrence G, Kearins O, Lagord C, Cheung S, Sidhu J, Sagar C. The Second All Breast Cancer Report. 2011. Available from: http://www. wmciu.nhs.uk/documents/Second ABCR.pdf. Accessed March 16, 2015.

2. Jeevan R, Cromwell D, Browne J, et al. National Mastectomy and Breast Reconstruction Audit (3rd Annual Report). The Royal College of Surgeons of England; 2010. Available from: http://www.rcseng. ac.uk/library-and-publications/college-publications/docs/mastectomybreast-3/. Accessed January 16, 2017.

3. Antony AK, Mehrara BM, McCarthy CM, et al. Salvage of tissue expander in the setting of mastectomy flap necrosis: a 13-year experience using timed excision with continued expansion. Plast Reconstr Surg. 2009;124(2):356-363.

4. Patel KM, Hill LM, Gatti ME, Nahabedian MY. Management of massive mastectomy skin flap necrosis following autologous breast reconstruction. Ann Plast Surg. 2012;69(2):139-144.

5. Margulies AG, Hochberg J, Kepple J, Henry-Tillman RS, Westbrook $\mathrm{K}$, Klimberg VS. Total skin-sparing mastectomy without preservation of the nipple-areola complex. Am J Surg. 2005;190(6):907-912.

6. Garwood ER, Moore D, Ewing C, et al. Total skin-sparing mastectomy: complications and local recurrence rates in 2 cohorts of patients. Ann Surg. 2009;249(1):26-32.

7. Meretoja TJ, Rasia S, von Smitten KA, Asko-Seljavaara SL, Kuokkanen HO, Jahkola TA. Late results of skin-sparing mastectomy followed by immediate breast reconstruction. Br J Surg. 2007;94(10):1220-1225.

8. Munhoz AM, Arruda E, Montag E, et al. Immediate skin-sparing mastectomy reconstruction with deep inferior epigastric perforator (DIEP) flap. Technical aspects and outcome. Breast J. 2007;13(5):470-478.

9. Nykiel M, Sayid Z, Wong R, Lee GK. Management of mastectomy skin flap necrosis in autologous breast reconstruction. Ann Plast Surg. 2014;72(suppl 1):S31-S34.

10. Matsen CB, Mehrara B, Eaton A, et al. Skin flap necrosis after mastectomy with reconstruction: a prospective study. Ann Surg Oncol. 2016;23(1):257-264.
11. Lee KT, Pyon JK, Bang SI, Lee JE, Nam SJ, Mun GH. Does the reconstruction method influence development of mastectomy flap complications in nipple-sparing mastectomy? J Plast Reconstr Aesthet Surg. 2013;66(11):1543-1550.

12. Sullivan SR, Fletcher DR, Isom CD, Isik FF. True incidence of all complications following immediate and delayed breast reconstruction. Plast Reconstr Surg. 2008;122(1):19-28.

13. Alderman AK, Wilkins EG, Kim HM, Lowery JC. Complications in postmastectomy breast reconstruction: two-year results of the Michigan Breast Reconstruction Outcome Study. Plast Reconstr Surg. 2002;109(7):2265-2274.

14. McCarthy CM, Mehrara BJ, Riedel E, et al. Predicting complications following expander/implant breast reconstruction: an outcomes analysis based on preoperative clinical risk. Plast Reconstr Surg. 2008;121(6):1886-1892.

15. Cordeiro PG, McCarthy CM. A single surgeon's 12-year experience with tissue expander/implant breast reconstruction: part I. A prospective analysis of early complications. Plast Reconstr Surg. 2006;118(4):825-831.

16. Gatzoulis MA. Chest wall and breast. In: Standring S, editor. Gray's Anatomy. 40th ed. London: Churchill Livingstone; 2008.

17. Palmer JH, Taylor GI. The vascular territories of the anterior chest wall. Br J Plast Surg. 1986;39(3):287-299.

18. Maliniac JW. Arterial blood supply of the breast: revised anatomic data relating to reconstructive surgery. Arch Surg. 1943;47(4):329-343.

19. Lemaine V, Hoskin TL, Farley DR, et al. Introducing the SKIN score: a validated scoring system to assess severity of mastectomy skin flap necrosis. Ann Surg Oncol. 2015;22(9):2925-2932.

20. Peled AW, Stover AC, Foster RD, McGrath MH, Hwang ES. Long-term reconstructive outcomes after expander-implant breast reconstruction with serious infectious or wound-healing complications. Ann Plast Surg. 2012;68(4):369-373.

21. Hultman CS, Daiza S. Skin-sparing mastectomy flap complications after breast reconstruction: review of incidence, management, and outcome. Ann Plast Surg. 2003;50(3):249-255. discussion 55.

22. Wilson CR, Brown IM, Weiller-Mithoff E, George WD, Doughty JC. Immediate breast reconstruction does not lead to a delay in the delivery of adjuvant chemotherapy. Eur J Surg Oncol. 2004;30(6):624-627.

23. ASPS. Plastic Surgery Statistics Report. Arlington Heights, IL, USA, American Society of Plastic Surgeons; 2012.

24. Vardanian AJ, Clayton JL, Roostaeian J, et al. Comparison of implantbased immediate breast reconstruction with and without acellular dermal matrix. Plast Reconstr Surg. 2011;128(5):403e-410e.

25. Hvilsom GB, Friis S, Frederiksen K, et al. The clinical course of immediate breast implant reconstruction after breast cancer. Acta Oncol. 2011;50(7):1045-1052.

26. della Rovere GQ, Nava M, Bonomi R, Catanuto G, Benson JR. Skinreducing mastectomy with breast reconstruction and sub-pectoral implants. J Plast Reconstr Aesthet Surg. 2008;61(11):1303-1308.

27. Gandhi A, Barr L, Johnson R. Bioprosthetics: changing the landscape for breast reconstruction? Eur J Surg Oncol. 2013;39(1):24-25.

28. Santanelli F, Longo B, Sorotos M, Farcomeni A, Paolini G. Flap survival of skin-sparing mastectomy type IV: a retrospective cohort study of 75 consecutive cases. Ann Surg Oncol. 2013;20(3):981-989.

29. Greer S, Morris T, Pettingale KW. Psychological response to breast cancer: effect on outcome. Lancet. 1979;2(8146):785-787.

30. Green BL, Rowland JH, Krupnick JL, et al. Prevalence of posttraumatic stress disorder in women with breast cancer. Psychosomatics. 1998;39(2):102-111.

31. Rosson GD, Shridharani SM, Magarakis M, et al. Quality of life before reconstructive breast surgery: a preoperative comparison of patients with immediate, delayed, and major revision reconstruction. Microsurgery. 2013;33(4):253-258.

32. Lawson EH, Hall BL, Louie R, et al. Association between occurrence of a postoperative complication and readmission: implications for quality improvement and cost savings. Ann Surg. 2013;258(1):10-18.

33. Yalanis GC, Nag S, Georgek JR, et al. Mastectomy weight and tissue expander volume predict necrosis and increased costs associated with breast reconstruction. Plast Reconstr Surg Glob Open. 2015;3(7):e450. 
34. NHSEngland. Five Year Forward View. 2014. Available from: http:// www.england.nhs.uk/wp-content/uploads/2014/10/5yfv-web.pdf. Accessed January 16, 2017.

35. Pinsolle V, Grinfeder C, Mathoulin-Pelissier S, Faucher A. Complications analysis of 266 immediate breast reconstructions. J Plast Reconstr Aesthet Surg. 2006;59(10):1017-1024.

36. Chang DW, Reece GP, Wang B, et al. Effect of smoking on complications in patients undergoing free TRAM flap breast reconstruction. Plast Reconstr Surg. 2000;105(7):2374-2380.

37. Mlodinow AS, Fine NA, Khavanin N, Kim JY. Risk factors for mastectomy flap necrosis following immediate tissue expander breast reconstruction. J Plast Surg Hand Surg. 2014;48(5):322-326.

38. Woerdeman LA, Hage JJ, Hofland MM, Rutgers EJ. A prospective assessment of surgical risk factors in 400 cases of skin-sparing mastectomy and immediate breast reconstruction with implants to establish selection criteria. Plast Reconstr Surg. 2007;119(2):455-463.

39. Nolan J, Jenkins RA, Kurihara K, Schultz RC. The acute effects of cigarette smoke exposure on experimental skin flaps. Plast Reconstr Surg. 1985;75(4):544-551.

40. Carlson GW. Trends in autologous breast reconstruction. Semin Plast Surg. 2004;18(2):79-87.

41. Goodwin SJ, McCarthy CM, Pusic AL, et al. Complications in smokers after postmastectomy tissue expander/implant breast reconstruction. Ann Plast Surg. 2005;55(1):16-19. discussion 9-20.

42. Abedi N, Ho AL, Knox A, et al. Predictors of mastectomy flap necrosis in patients undergoing immediate breast reconstruction: a review of 718 patients. Ann Plast Surg. 2016;76(6):629-634.

43. Phillips BT, Lanier ST, Conkling N, et al. Intraoperative perfusion techniques can accurately predict mastectomy skin flap necrosis in breast reconstruction: results of a prospective trial. Plast Reconstr Surg. 2012;129(5):778e-788e.

44. Chun YS, Verma K, Rosen H, et al. Use of tumescent mastectomy technique as a risk factor for native breast skin flap necrosis following immediate breast reconstruction. Am J Surg. 2011;201(2):160-165.

45. Khavanin N, Jordan S, Lovecchio F, Fine NA, Kim J. Synergistic interactions with a high intraoperative expander fill volume increase the risk for mastectomy flap necrosis. J Breast Cancer. 2013;16(4):426-431.

46. Agarwal T, Hultman CS. Impact of radiotherapy and chemotherapy on planning and outcome of breast reconstruction. Breast Dis. 2002;16:37-42.

47. Habermann EB, Abbott A, Parsons HM, Virnig BA, Al-Refaie WB, Tuttle TM. Are mastectomy rates really increasing in the United States? J Clin Oncol. 2010;28(21):3437-3441.

48. Davies K, Allan L, Roblin P, Ross D, Farhadi J. Factors affecting post-operative complications following skin sparing mastectomy with immediate breast reconstruction. Breast. 2011;20(1):21-25.

49. Chang DW, Wang B, Robb GL, et al. Effect of obesity on flap and donor-site complications in free transverse rectus abdominis myocutaneous flap breast reconstruction. Plast Reconstr Surg. 2000;105(5) 1640-1648.

50. Spear SL, Ducic I, Cuoco F, Taylor N. Effect of obesity on flap and donor-site complications in pedicled TRAM flap breast reconstruction. Plast Reconstr Surg. 2007;119(3):788-795.

51. Mehrara BJ, Santoro TD, Arcilla E, Watson JP, Shaw WW, Da Lio AL. Complications after microvascular breast reconstruction: experience with 1195 flaps. Plast Reconstr Surg. 2006;118(5):1100-1109. discussion 1110-1111.

52. Kroll SS, Netscher DT. Complications of TRAM flap breast reconstruction in obese patients. Plast Reconstr Surg. 1989;84(6):886-892.

53. Gould DJ, Hunt KK, Liu J, et al. Impact of surgical techniques, biomaterials, and patient variables on rate of nipple necrosis after nipple-sparing mastectomy. Plast Reconstr Surg. 2013;132(3):330e-338e.

54. Paige KT, Bostwick J 3rd, Bried JT, Jones G. A comparison of morbidity from bilateral, unipedicled and unilateral, unipedicled TRAM flap breast reconstructions. Plast Reconstr Surg. 1998;101(7):1819-1827.

55. Padubidri AN, Yetman R, Browne E, et al. Complications of postmastectomy breast reconstructions in smokers, ex-smokers, and nonsmokers. Plast Reconstr Surg. 2001;107(2):342-349.
56. Losken A, Styblo TM, Schaefer TG, Carlson GW. The use of fluorescein dye as a predictor of mastectomy skin flap viability following autologous tissue reconstruction. Ann Plast Surg. 2008;61(1):24-29.

57. Heliovaara M, Karvonen MJ, Vilhunen R, Punsar S. Smoking, carbon monoxide, and atherosclerotic diseases. Br Med J. 1978;1(6108):268-270.

58. Hawkins RI. Smoking, platelets and thrombosis. Nature. 1972; 236(5348):450-452.

59. Levine PH. An acute effect of cigarette smoking on platelet function. A possible link between smoking and arterial thrombosis. Circulation 1973;48(3):619-623.

60. Mills E, Eyawo O, Lockhart I, Kelly S, Wu P, Ebbert JO. Smoking cessation reduces postoperative complications: a systematic review and meta-analysis. Am J Med. 2011;124(2):144.e8-154.e8.

61. Manchio JV, Litchfield CR, Sati S, Bryan DJ, Weinzweig J, Vernadakis AJ. Duration of smoking cessation and its impact on skin flap survival Plast Reconstr Surg. 2009;124(4):1105-1117.

62. Kempton SJ, Burish NM, Rao VK. Electronic cigarettes: have you asked your patients about vaping? Plast Reconstr Surg. 2014;133(6):907e.

63. Khansa I, Colakoglu S, Curtis MS, et al. Postmastectomy breast reconstruction after previous lumpectomy and radiation therapy: analysis of complications and satisfaction. Ann Plast Surg. 2011;66(5):444-451.

64. Chang EI, Vaca L, DaLio AL, Festekjian JH, Crisera CA. Assessment of advanced age as a risk factor in microvascular breast reconstruction. Ann Plast Surg. 2011;67(3):255-259.

65. Miller RB, Reece G, Kroll SS, et al. Microvascular breast reconstruction in the diabetic patient. Plast Reconstr Surg. 2007;119(1):38-45. discussion 6-8.

66. Vargas CR, Koolen PG, Anderson KE, et al. Mastectomy skin necrosis after microsurgical breast reconstruction. J Surg Res. 2015; 198(2):530-534

67. Meretoja TJ, von Smitten KA, Kuokkanen HO, Suominen SH, Jahkola TA. Complications of skin-sparing mastectomy followed by immediate breast reconstruction: a prospective randomized study comparing high-frequency radiosurgery with conventional diathermy. Ann Plast Surg. 2008;60(1):24-28.

68. Rinker B, Thornton BP. Skin-sparing mastectomy and immediate tissue expander breast reconstruction in patients with macromastia using the Passot breast reduction pattern. Ann Plast Surg. 2014;72(6):S158-S164.

69. Peled AW, Foster RD, Ligh C, Esserman LJ, Fowble B, Sbitany H. Impact of total skin-sparing mastectomy incision type on reconstructive complications following radiation therapy. Plast Reconstr Surg. 2014;134(2):169-175.

70. Robertson SA, Rusby JE, Cutress RI. Determinants of optimal mastectomy skin flap thickness. Br J Surg. 2014;101(8):899-911.

71. Larson D, Basir Z, Bruce T. Is oncologic safety compatible with a predictably viable mastectomy skin flap? Plast Reconstr Surg. 2011; 127(1):27-33.

72. Beer GM, Varga Z, Budi S, Seifert B, Meyer VE. Incidence of the superficial fascia and its relevance in skin-sparing mastectomy. Cancer. 2002;94(6):1619-1625.

73. O'Connell RL, Rusby JE. Anatomy relevant to conservative mastectomy. Gland Surg. 2015;4(6):476-483.

74. Verheyden CN. Nipple-sparing total mastectomy of large breasts: the role of tissue expansion. Plast Reconstr Surg. 1998;101(6):1494-1500. discussion 501-502.

75. Newman LA, Kuerer HM, Hunt KK, et al. Presentation, treatment, and outcome of local recurrence after skin-sparing mastectomy and immediate breast reconstruction. Ann Surg Oncol. 1998;5(7):620-626.

76. Kroll SS, Ames F, Singletary SE, Schusterman MA. The oncologic risks of skin preservation at mastectomy when combined with immediate reconstruction of the breast. Surg Gynecol Obstet. 1991;172(1):17-20.

77. Moyer HR, Losken A. Predicting mastectomy skin flap necrosis with indocyanine green angiography: the gray area defined. Plast Reconstr Surg. 2012;129(5):1043-1048.

78. Wang F, Peled AW, Garwood E, et al. Total skin-sparing mastectomy and immediate breast reconstruction: an evolution of technique and assessment of outcomes. Ann Surg Oncol. 2014;21(10):3223-3230. 
79. Di Candia M, Lie KH, Forouhi P, Malata CM. Experience with the Wise mammaplasty skin resection pattern in skin-sparing mastectomy and immediate breast reconstruction for large breast volumes. Int $J$ Surg. 2011;9(1):41-45.

80. Khavanin N, Fine NA, Bethke KP, et al. Tumescent technique does not increase the risk of complication following mastectomy with immediate reconstruction. Ann Surg Oncol. 2014;21(2):384-388.

81. Carlson GW, Chu CK, Moyer HR, Duggal C, Losken A. Predictors of nipple ischemia after nipple sparing mastectomy. Breast J. 2014;20(1):69-73.

82. Gurtner GC, Jones GE, Neligan PC, et al. Intraoperative laser angiography using the SPY system: review of the literature and recommendations for use. Ann Surg Innov Res. 2013;7(1):1.

83. Barber MD, Williams L, Anderson ED, et al. Outcome of the use of acellular-dermal matrix to assist implant-based breast reconstruction in a single centre. Eur J Surg Oncol. 2015;41(1):100-105.

84. Jallali N, Ridha H, Butler PE. Postoperative monitoring of free flaps in UK plastic surgery units. Microsurgery. 2005;25(6):469-472.

85. Mothes H, Donicke T, Friedel R, Simon M, Markgraf E, Bach O. Indocyanine-green fluorescence video angiography used clinically to evaluate tissue perfusion in microsurgery. JTrauma. 2004;57(5):1018-1024.

86. Olivier WA, Hazen A, Levine JP, Soltanian H, Chung S, Gurtner GC. Reliable assessment of skin flap viability using orthogonal polarization imaging. Plast Reconstr Surg. 2003;112(2):547-555.

87. Hallock GG. Doppler sonography and color duplex imaging for planning a perforator flap. Clin Plast Surg. 2003;30(3):347-57, v-vi.

88. Heden P, Jurell G, Arnander C. Prediction of skin flap necrosis: a comparative study between laser Doppler flowmetry and fluorescein test in a rat model. Ann Plast Surg. 1986;17(6):485-488.

89. Schlosser S, Wirth R, Plock JA, Serov A, Banic A, Erni D. Application of a new laser Doppler imaging system in planning and monitoring of surgical flaps. J Biomed Opt. 2010;15(3):036023.

90. Rubben A, Eren S, Krein R, Younossi H, Bohler U, Wienert V. Infrared videoangiofluorography of the skin with indocyanine green - rat random cutaneous flap model and results in man. Microvasc Res. 1994;47(2):240-251.

91. May JW Jr, Chait LA, O’Brien BM, Hurley JV. The no-reflow phenomenon in experimental free flaps. Plast Reconstr Surg. 1978;61(2): 256-267.

92. Newman MI, Samson MC, Tamburrino JF, Swartz KA. Intraoperative laser-assisted indocyanine green angiography for the evaluation of mastectomy flaps in immediate breast reconstruction. J Reconstr Microsurg. 2010;26(7):487-492.

93. Sood M, Glat P. Potential of the SPY intraoperative perfusion assessment system to reduce ischemic complications in immediate postmastectomy breast reconstruction. Ann Surg Innov Res. 2013;7(1):9.
94. Wapnir I, Dua M, Kieryn A, et al. Intraoperative imaging of nipple perfusion patterns and ischemic complications in nipple-sparing mastectomies. Ann Surg Oncol. 2014;21(1):100-106.

95. Kanuri A, Liu AS, Guo L. Whom should we SPY? A cost analysis of laser-assisted indocyanine green angiography in prevention of mastectomy skin flap necrosis during prosthesis-based breast reconstruction. Plast Reconstr Surg. 2014;133(4):448e-454e.

96. Rao R, Saint-Cyr M, Ma AM, et al. Prediction of post-operative necrosis after mastectomy: a pilot study utilizing optical diffusion imaging spectroscopy. World J Surg Oncol. 2009;7:91.

97. Mauri D, Pavlidis N, Ioannidis JP. Neoadjuvant versus adjuvant systemic treatment in breast cancer: a meta-analysis. J Natl Cancer Inst. 2005;97(3):188-194.

98. Fontein DB, Charehbili A, Nortier JW, et al. Efficacy of six month neoadjuvant endocrine therapy in postmenopausal, hormone receptor-positive breast cancer patients - a phase II trial. Eur J Cancer. 2014;50(13): 2190-2200.

99. Carpenter R, Doughty JC, Cordiner C, et al. Optimum duration of neoadjuvant letrozole to permit breast conserving surgery. Breast Cancer Res Treat. 2014;144(3):569-576.

100. Gdalevitch P, Van Laeken N, Bahng S, et al. Effects of nitroglycerin ointment on mastectomy flap necrosis in immediate breast reconstruction: a randomized controlled trial. Plast Reconstr Surg. 2015;135(6):1530-1539.

101. Vilar-Compte D, Castillejos A, Hernandez-Mello N, Robles-Vidal C, Volkow P. Characteristics and treatment of surgical site complications in patients undergoing mastectomy at a cancer hospital in Mexico. Wounds. 2010;22(12):316-321.

102. Fredman R, Wise I, Friedman T, Heller L, Karni T. Skin-sparing mastectomy flap ischemia salvage using urgent hyperbaric chamber oxygen therapy: a case report. Undersea Hyperb Med. 2014;41(2): $145-147$.

103. Mermans JF, Tuinder S, von Meyenfeldt MF, van der Hulst RR. Hyperbaric oxygen treatment for skin flap necrosis after a mastectomy: a case study. Undersea Hyperb Med. 2012;39(3):719-723.

104. Reichl H, Hladik M, Wechselberger G. Skin banking: treatment option for native skin necrosis following skin-sparing mastectomy and previous breast irradiation. Microsurgery. 2011;31(4):314-317.

105. Heller KS, Slattery LR, Harris MN. Use of a questionably viable flap as a full thickness skin graft after mastectomy. Surg Gynecol Obstet. 1976;143(1):94-96.

106. Jensen JA, Lin JH, Kapoor N, Giuliano AE. Surgical delay of the nipple-areolar complex: a powerful technique to maximize nipple viability following nipple-sparing mastectomy. Ann Surg Oncol. 2012;19(10): 3171-3176.
Breast Cancer - Targets and Therapy

\section{Publish your work in this journal}

Breast Cancer - Targets and Therapy is an international, peerreviewed open access journal focusing on breast cancer research, identification of therapeutic targets and the optimal use of preventative and integrated treatment interventions to achieve improved outcomes, enhanced survival and quality of life for the cancer patient.

\section{Dovepress}

The manuscript management system is completely online and includes a very quick and fair peer-review system, which is all easy to use. Visit http://www.dovepress.com/testimonials.php to read real quotes from published authors. 